\title{
Функционирование топонимов и этнонимов в речи литовцев Латвии
}

\author{
РЕГИНА КВАШИТЕ \\ Šiauliu universitetas, Humanitarinis fakultetas, P. Višinskio g. 38, \\ LT-76352 Šiauliai,Lietuva,kvasyte@hu.su.lt
}

SCN III/1 [2010], 147-177

\begin{abstract}
Članek obravnava leksiko Litovcev v Latviji. Pozornost je posvečena dvema specifičnima plastema besedišča - toponimom in etnonimom. V raziskavi je bilo ugotovljeno, da spekter toponimov ni širok, saj med posameznimi naselji in njim bližnjimi področji prevladujejo imena obeh držav, etnonimi pa razkrivajo zanimive težnje, ki izkazujejo nasprotje domače - tuje.
\end{abstract}

The article deals with the research of lexis of Lithuanians in Latvia: attention is paid to two specific layers of vocabulary - toponyms and ethnonyms. During the research of toponyms, it was found out that the spectrum of toponyms was not very wide: the titles of both states dominated and among particular settlements - populated localities and those territorially close to them. Functioning of ethnonyms discloses interesting tendencies manifesting the opposition "nativeoutlandish".

Ključne besede: jezik Litovcev v Latviji, toponimi, etnonimi, konkurenčni leksemi

Key words: the language of Lithuanians in Latvia, toponyms, ethnonyms, competitors

\section{Вводные замечания}

Тенденция переселяться из родных мест не обошла стороной и литовцев, коренных жителей Литвы - часть из них в разные исторические отрезки времени своим новым местом проживания выбрали соседнее государство Латвию. Больше всего литовцев переселялось в крупные города страны - в Ригу, Лиепаю, Елгаву и другие места Латвии в 1880-1914 гг. (Garšva 2005: 20). Особенно интенсивно подобное переселение проходило после второй мировой войны, часто по экономическим причинам (уровень прожива- 
ния в Латвии в то время был выше) и политическим мотивам (многим литовцам не было дозволено вернуться на родину из ссылки и после отбывания срока в лагерях в годы сталинских репрессий). Поэтому среди представителей около 100 национальностей, проживающих в Латвии, все время были литовцы. Как показывают новейшие данные Управления по статистике, на начало 2009 года их количество составляло около 1,3\% всех жителей (2 261294$)$ - это пятое по величине национальное меньшинство Латвии (30 415) (Статистика 2009). Наибольшее количество литовцев проживает в столице и других крупных городах Латвии (это объясняется в первую очередь экономическими причинами - возможностью устроиться на работу и получить жилье), а также в приграничных с Литвой районах как территориально наиболее приближенных к родным краям.

$\mathrm{C}$ научной точки зрения проживающие за пределами своей страны люди являются интересным объектом исследования, а среди разнообразных исследований особый интерес представляет изучение языка как важнейшего показателя этничности. Такие исследования позволяют выяснить, насколько и в каком качестве сохранился родной язык (диалект) литовцев и каковы возможности и условия функционирования их речи. Чаще всего внимания лингвистов заслуживает фонетика как показатель устойчивости языковой системы родного языка. Интерес представляет также наиболее легко поддающийся изменениям уровень языка - лексика. Кроме того имеются некоторые публикации и о других уровнях родного языка проживающих в Латвии литовцев (Grinaveckienè 1980; Garšva 2005). Следует также отметить факт, что этими вопросами интересуются в основном литовские языковеды, но исследования публикуются на разных языках: литовском, латышском, русском, немецком. Так, например, лексика литовцев Латвии анализировалась с точки зрения отражения языковых контактов (Kvašytė 1997; Kvašīte 2002; Kvašyte 2006; Kvašīte 2007) или как содержащая в себе заимствованные из латышского языка слова (Kvašytė 2001). Отдельно описывалось функционирование названий реалий общественной жизни (Квашите 2003b), анализировались также социолингвистический и лингвистический аспекты речи (Квашите 2003a), а новейшая публикация посвящена вопросам синтаксиса - употреблению предлогов (Kvašytė 2009).

\section{Цель, методика и материал исследования}

Данная статья посвящается лексическому уровню языка, но внимание сосредоточено на связанных между собой специфических пластах словарного состава - названиях стран, городов и т. п. (топонимии) и названиях национальностей (этнонимии). Цель данного исследования: установить, насколько популярны в разговорной речи литовцев Латвии географические названия и названия разных национальностей и в каком контексте они функционируют. Исследование проводилось методом качественного, 
лексико-семантического анализа (не использовался метод количественного анализа, так как не ставилось целью установить частотность употребления того или другого слова, а лишь выяснить их разнообразие; все же при описании учитывалось и распространение данных слов). Материал для исследования собирался в основном на приграничных с Литвой территориях (Салдусский р-н поблизости к Мажейкяй с литовской стороны и Добельский р-н поблизости к Жагаре), куда соответственно в 1993 и 1995 гг. отправлялись экспедиции студентов Шяуляйского педагогического института (с 1997 г. Шяуляйский университет), а также отдельные зафиксированные личные наблюдения за речью проживающих в городе Риге литовцев в течении 1993-2003 гг. Таким образом часть материала собрано из районов, где литовцы проживают достаточно компактно (приграничье), а другая часть из вразброс проживающих в столице информантов, возможности которых общаться на родном языке более ограничены. Использование такой неоднородной выборки данных не дает основания делать серьезные обобщения, но позволяет взглянуть на тенденции функционирования данного пласта лексики.

Анализируемые далее примеры условно обозначаются соответствующими названиям местностей на латышском (и литовском) языке буквами латинского алфавита: В - Bukaiši (Букайши - населенный пункт в 7 км от границы в Жагаре), R - Ruba (Руба - населенный пункт в 3 км от границы в Лайжува) и $\mathrm{Rg}-\mathrm{Rĭga}$ (Рига - столица Латвии). Статистические данные свидетельствуют, что большинство литовцев Латвии проживает именно в Дуобельском районе $(6,3 \%)$, а в посещенном участниками экспедиции селе Букайши даже 13,9\% населения литовцы (Butkus 1995: 73).

\section{Топонимы и их конкуренты в речи литовцев}

Топонимика как совокупность географических названий какой-либо местности (Ахманова 2004: 477) по величине называемых объектов распадает на два пласта: макротопонимы и микротопонимы. Макротопонимы (от греч. makros - «большой», topos - «место», «местность» и опута - «имя») - собственные имена крупных географических объектов, например, стран или исторических областей. В свою очередь микротопонимы (от греч. mikros - «малый», topos - «место», «местность» и опута - «имя») - собственные имена небольших географических объектов, таких как луг, пастбище, колодец, топь, выгон и тому подобные (Ономастика). Анализ собранного материала показал, что из макротопонимов доминируют названия обеих стран, т. е. Латвия и Литва, кроме того часто употреблялись названия Сибирь и Россия как обобщенные обозначения мест ссылки. Все-таки выяснилось, что собранный материал нецелесообразно рассматривать, распределив его на названия крупных и мелких объектов (соответственно анализировать макро- и микротопонимы), более обоснованной показалась их классификация в зависимости от 
территориальной принадлежности конкретного топонима. Таким образом данная совокупность лексики по разным критериям может быть распределена на несколько групп. Во-первых, информанты часто в своей речи упоминали название страны проживания (Latvija) и ее населенные пункты. Во-вторых, встречаются названия страны, откуда родом информанты (Lietuva) и населенные пункты Литвы; и, в-третьих, но достаточно редко, названия мест ссылки или заключения, а также другие места проживания за пределами Литвы и Латвии.

Название страны проживания (в обоих языках данный топоним имеет одинаковую форму Latvija) и населенные пункты Латвии - прежде всего местности, где проживают информанты, или расположенные поблизости места, с которыми тем или другим способом связана жизнь, например, где проживают или раньше проживали они сами или их родственники, так как рассказ в основном строился на личных воспоминаниях и т. п. Поэтому в речи проживающих в Букайши чаще всего встречаются топонимы Дуобельского района, а в Рубе - Салдусского района. Кроме того, довольно часто все информанты употребляют название столицы Латвии города Риги (лат. Rīga; лит. Ryga):

Pinigu nemokejo /Lietuvoje už darbą/, dèl to ir éjome čia, i Lat vija. [Денег не

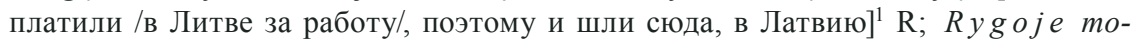
kinosi par girininku. [В Риге учился на лесничего] В; Pas mus Bukaičiuose sutiksi daug lietuvių. [У нас в Букайшах встретишь много литовцев] В; Siena visai prie mūsu padarè, Ru boje gyvename. [Границу совсем рядом с нами сделали, в Рубе живем] R; Kas neina i mokykla čia, mokinasi Augstkalnej j [Кто не ходит в школу здесь, учится в Аугсткалне] В; I D u ob elę ne kasdien gali nuvažiuoti, kai turi koki gyvuli namuose [В Дуобеле не каждый день можешь поехать, если имеешь дома какой-либо скот] В.

Некоторые из употребленных в приведенных выше предложениях топонимы употреблены в форме литовского языка, например, Bukaičiai имеет свойственное для литовских названий формы множественного числа суффикс-aičiai, в свою очередь в латышском языке употребляется свойственный суффикс -aiši, хотя в данном случае в латышском названии следовало лишь изменить окончание Bukaišiai. Другие топонимы часто имеют свойственную для разговорной речи форму с сокращенным окончанием местного падежа: Augstkalnëj вместо полной формы Augstkalnëje.

В записях, сделанных в Рубе и Букайши, почти не упоминались микротопонимы. Вероятно информанты заранее настраивали себя на то, что слушатели (берущие интервью) недостаточно хорошо знакомы с окрестностями, поэтому старались строить повествование так, чтобы меньше употреблять географических названий - иногда заменяли имена

\footnotetext{
${ }^{1}$ Приведенные из записей высказываний информантов предложеня на литовском языке переведены на русский язык в основном дословно, чтобы ознакомить читателя с содержанием высказывания.
} 
собственные номенклатурными аппелятивами, например, miškas (лес), ežeras (озеро), ире (река). В свою очередь в ходе наблюдений за речью проживающих в Риге литовцев удалось установить случаи употребления микротопонимов - названий районов города (Imanta (Иманта), Pliavniekai (лат. Plavnieki; Плявниеки), Kypsala (лат. Ǩ̈psala; Кипсала)) и окрестностей Риги (Baluožiai (лат. Baloži; Баложи), Kekava (лат. Ķekava; Кекава), Ramava (лат. Rāmava; Рамава)), а также названия улиц:

\begin{abstract}
Anksčiau, kai gyvenom Im a nte, mes dažniau susitikom. [Раньше, когда жили в Иманте, мы чаще встречались] Rg; Nesulaukiu, kada pagaliau Virgis parduos buta Pliavniekuos. [Не дождусь, когда Виргис наконец продаст квартиру в Плявниеки] Rg; Ar tau negaila gyvenimo Ram avoj? [Не жаль ли тебе жизни в Рамаве?] Rg; Kaip Ki p s a la dabar išsimaine, negali nieko pažinti. [Как Кипсала теперь изменилась, ничего узнать нельзя] $\mathrm{Rg}$; Atsimeni, važiuodavome Ap $\bar{u} z$ es gatve pas mus. [Помнишь, ездили по улице Апузес к нам] Rg.
\end{abstract}

Из приведенного выше первого примера видно, что говорящий на литовском языке информант вместо названия, которое в латышском языке женского рода (Imanta и соответственно форма местного падежа должна быть Imantoje) употребляет данный топоним как существительное мужского рода, поэтому так его склоняет (Imantas - Imante). Остальные микротопонимы могут варьировать в зависимости от более или менее точной передачи формы латышского языка на литовский (например, встречаются две формы названия Ǩ̈psala - соответственно с долгим гласным (Kypsala) или кратким гласным (Kipsala) в корне топонима).

Кроме широко распространенных в рассказах литовцев и наблюдениях за их речью топонимов страны (места) проживания встречаются также названия страны происхождения (Lietuva) и населенных пунктов Литвы:

Mums baise švake bova Li e tuv u o. [Нам очень худо было в Литве] R; Mano tèvas buvo iš L i et uvos, ir motina - iš Ig nali nos ... [Мой отец был из Литвы, и матьиз Игналины....] В; Mes su kojom $i \check{Z}$ a ga re eidavom. [Мы пешком ходили в Жагаре] $\mathrm{B}$; Viena atejjo iš toliau, iš Akme nès miesto atvažiavo. [Одна пришла из далека, из города Акмяне приехала] В; ... žiūrèjom, kaip išvežè, išvežè i Mažeikius, ten $\operatorname{tarde}$... [... смотрели, как увезли, увезли в Мажейкяй, там допрашивали...] В.

В записях речи информантов доминируют географические названия, которые раскрывают их личный опыт, т. е. непосредственно касаются их или членов семьи. В первую очередь это места рождения и проживания или населенные пункты, находящиеся поблизости к месту теперешнего проживания. В приведенном выше примере упоминается название города Akmene (Акмяне), основанного в начале XVI в. Следует отметить, что топонимов, имеющих корень akmen- в Литве насчитывается сотнями. Нет сомнений, что большинство их происходят из слова $a k m u о$ («камень»), но часть их может быть и гидронимного происхождения. Все-же нет оснований утверждать, что к ним принадлежит и упоминаемое в материале речи пограничья литовцев Латвии название города на севере Литвы (Vanagas 1996: 15). Другой топоним - Ignalina (Игналина) - называет один из но- 
вейших городов Литвы. Его название впервые упоминается в 1810 г., а происходит от антропонима, вероятно уменьшительной формы мужского имени Ignas - Ignelis (Игнас - Игнелис). Это может быть связано с именем помещика Игнаса Тизенгауза (Ignas Tyzenhauzas) (Vanagas 1996: 77). В свою очередь название Žagare (Жагаре) в исторических источниках упоминается в 1253 или 1254 гг. Данный топоним, по-видимому, производное с окончанием - $\dot{e}$ слово из литовского аппелятива žagaras («хворостина»). Первичное название может быть «место, где много хворостины» (Vanagas 1996: 297-298).

В отражающей функционирование топонимов выборке иногда встречаются и названия мест ссылки или заключения. Информанты в своих рассказах в основном упоминали названия крупных географических объектов: Sibiras (Cибирь) и Rusija (Россия), реже - конкретные места проживания:

Parei iš to Si bire, kur dèsies. [Вернулись из Сибири, куда денешся] В; Sunku mums $R$ u s i joj buvo, net prisiminti nesinori. [Трудно нам в России было, даже вспоминать не хочется] Rg; ... žiürëjom, kaip išvežè, išveže i Mažeikius, ten tardè, nu ir paskum išveže i Archangelska. [... смотрели, как увезли, увезли в Мажейкяй, там допрашивали, о потом увезли в Архангельск] B; Taip mes ir susipažinome lageryje, In toje. [Так мы и познакомились в лагере, в Инте] Rg.

В ходе опроса информантов и наблюдения за их свободной разговорной речью выявлено функционирование слов, заменяющих названные конкретные топонимы (уместно использовать заимствованный из области стилистики термин конкуренты (Župerka 1995)). Все же очевидно, что конкурентам названий места проживания несвойственна большая разнообразность. Чаще всего в подобной функции встречаются обстоятельства места с̌ia («здесь»), ten («там»).

Bet iš direktoriaus gavau tokị rašta, kad mano visi vaikai č i a yra pabaige mokyklas ... [Но от директора получила такое свидетельство, что все мои дети здесь закончили школы...] В; С̆ i a /Latvijoje/ ükininkai pirms kara irgi gyvena geriau ... [Здесь (в Латвии) хозяева до войны тоже жили лучше...] R; Kaip jūs te n gyvenate dabarseniai nebuvau. [Как вы там живете сейчас - давно не был] Rg.

Хотя сами по себе данные слова-конкуренты не представляют особого интереса, упомянутой паре антонимов все же присуща определенная специфика: в зависимости от того, какая страна (сторона) принимается за точку отсчета, и то, и другое обстоятельство места может обозначать как Латвию, где проживают информанты, так и Литву, откуда они родом. Более точная идентификация возможна лишь при помощи контекста.

В выборке материала очевидно преобладание названий населенных пунктов Латвии (чаще всего упоминаются местности, в которых в настоящее время проживают информанты), все-таки не очень отстают от них и географические названия Литвы - функционируют названия мест, откуда родом и где жили информанты или живут их родственники. В свою очередь третья група топонимов немногочисленна. Лишь в отдельных 
случаях информанты уточняли, конкретизировали место пребывания, в основном это им казалось неактуальным, точнее, они не думали, что это важно для их расспрашивающих людей. Лишь в тех случаях, когда запись велась незаметно для информанта, чаще встречалось упоминание конкретных географических названий.

\section{Этнонимы и их конкуренты в речи литовцев}

Другой пласт, отобранный для исследования - этнонимика, т. е., «раздел антропонимии, изучающий названия народов» (Ахманова 2004: 529). Названия народов (этнонимы) обычно соотносятся с макротопонимами, т. е., производятся от названий стран и «можно предположить, что множественное число первично для этнонимов» (Грищенко, Николина 2006: 175), поэтому в речи информантов редко встречается форма единственного числа соответствующих слов (чаще всего в тех случаях, когда речь идет о конкретном человеке). Хотя обычно в литовском языке именно единственное число имеет значение обобщения и может быть использовано по отношению к группе людей, а не только отдельного индивида.

В функционировании данного пласта лексики явно прослеживается оппозиция «свой-чужой». С одной стороны, информанты рассказывают о своей национальности - преимущественно в положительном контексте. Такая точка зрения опирается на мнение, что «всем народам свойственен этноцентризм - возвышение системы своих ценностей по отношению к другим культурам. Это основывается на крайне упрощенных категорических преположениях, которые называем стереотипами» (Anglickienè 2006: 65). Все-таки очевидно и то, что лишь более широкий контекст дает представление об отношении говорящего к содержанию высказывания и в частности, к употребленному этнониму.

Выборка материала раскрывает функционирование этнонимов для названия своей национальности. Хотя официальное название ее - производное от названия страны Lietuva слово lietuviai («литовцы»), информанты называли ее по-разному:

Mes, li etuviai, pilsonybès čia neturim. [Мы, литовцы, гражданства здесь не имеем] R; L i e tu via i dabar turi savo draugija - vaikštau ir aš [Литовцы сейчас имеют свое общество - хожу и я на собрания] Rg; Ankstiau če riktingi ž e ma i te gyvena. [Раньше здесь настоящие жемайты жили] R; Kas tu esi par le it is. [Какой ты литовец] В.

В определенном смысле слова есть повод рассматривать использованные в приведенных выше примерах слова žemaičiai («жемайты») и leiši (употреблена форма единственного числа leitis; на русский язык иначе чем литовец невозможно перевести) в качестве конкурентов. В первом случае этноним произведен от названия жителей этнографического региона Жемайтия (лит. Žemaitija) и носителей жемайтского диалекта. Следует от- 
метить факт, что часть жителей данного региона считают себя отдельным народом, в разные периоды истории Литвы имели место попытки создать самостоятельное государство, диалект называется языком и имеет письменную форму и т. п. Все-таки контекст позволяет утверждать, что данное слово информантом употреблено обобщенно - в значении «литовец».

Слово leiši с культурной и лингвистической точек зрения, как утверждает латышский фольклорист Янис Розенбергс - «старейший этноним для обозначения наших южных соседей» (Rozenbergs 2005: 21). Оно может употребляться в качестве названия проживающего в Литве народа вместо современного слова lietuvieši. Предлагается не рассматривать данное слово элементом «разговорного языка, имеющим пренебрежительный оттенок», а наоборот, возвратить «этому красивому слову Leiši его былую добрую славу, которая на веки веков закреплена и достойно утверждена в латышских народных песнях. Будем употреблять слово Leiši без предрассудков не только в повседневной жизни, но и в языке научных трудов!» (Rozenbergs 2005: 21). Все-таки данный этноним воспринимается многими литовцами, проживающими на территории Латвии и / или владеющими латышским языком как уничижительное и неуважительное. Поэтому зафиксированные случаи употребления информантами слова leiši могут иметь и положительную, и отрицательную, как в приведенном примере, коннотацию.

С другой стороны, актуализируется название народа страны проживания - производные от названия страны Latvija («Латвия») этнонимы latvietis («латыш») или во множественном числе latvieši («латыши»). Кроме того в разговорной речи функционирует на основе немецкого названия латышей Letten (название страны соответственно Lettland) образованное слово letinš (форма множественного числа letini). На выбор данного слова повлияло то, что так по разным поводам и с различными намерениями называют себя латыши (ни в литовском, ни в русском языке нет точных соответствий, как перевести данное слово, поэтому можно его лишь транслитерировать - «летини»).

Jonai pas la t vius riktinga šventè. [Иванов день у латышей настоящий праздник] $\mathrm{R}$; L a t vi a i yr laba lepni žmonès. [Латыши очень гордые люди] R; Toks la tvis mus priemé, kai čia atvažiavome. [Такой латыш нас принял, когда сюда приехали] B; Sédasi le tinia i prie stalo ir alaus bokalus kilnoja, dainas dainuoja. [Садятся латыши за стол и бокалы пива поднимают, песни поют] R.

Данная выборка дает возможность выяснить, как через сравнение литовцев и латышей проявляется попытка выразить оппозицию «свойчужой». Встречается и положительная, и отрицательная оценка своего народа, а также основанный на собственном опыте взгляд на представителей другого народа. «Члены общества могут исповедовать много разных установок по отношению к разным группам, они находят проявление в повседневной жизни, влияют на поведение и поступки, особенно очутившись в смешанной с точки зрения национальностей среде. Все же они 
могут не быть реализованы в повседневной жизни ... Часто высказывания тех же самых людей логически противоречат один другому, так как они в основном бывают обусловлены конкретными ситуациями, контекстом, в котором было выражено то или другое мнение.» (Anglickienė 2006: 68). Такие случаи имели место и в исследуемом материале, когда в одном случае свой народ возвышался, в другом - показывался как заслуживающий меньше уважения (об этом свидетельствует приведенное в качестве иллюстации первое предложение):

Su latvia is gali geriau sutarti nei su li et uvia is. [C латышами можно лучше найти общий язык чем с литовцами] $\mathrm{B}$; La t vi a i, kaip ir li e t u via i, j dieva tiki. [Латыши, как и литовцы, в бога верят] В; Par Kaledas la t vi a i taip pat eglutę turi. [На Рождество латыши также елку имеют] Rg.

Сравнение может быть имплицитно, т. е., не иметь формального выражения или это выражение будет через употребление других слов, как в последнем из приведенных выше предложений.

Другие этнонимы, встречающиеся в речи литовцев, связаны непосредственно с народами, представители которых проживают вместе с литовцами, а также такие, которые имеют устойчивые традиции проживания в определенном регионе в определенную историческую эпоху или тесные контакты с литовцами (иногда и с латышами). В данном случае речь идет о двух народах и соответственно называющих их этнонимах rusai («русские») и žydai («евреи»):

Pradejau girdèt, kad su r us u pasu nebeleis nuo pirmos /per sieną i Lietuvą - nuo rugpjūčio 1 d./. [Стала слышать, что с русским паспортом не будут пропускать через границу с первого /через границу в Литву - с 1-ого августа/] В; Žydai važinèjo su arkliu odas supirkdami. [Евреи ездили на лошадях и скупали кожи] В.

В приведенных выше предложениях функционируют имеющие нейтральную окраску этнонимы. Следует отметить, что название žydas (множественное число žydai) в литовском языке не имеет присущей для других языков, например, русского, негативной коннотации и неуважительного, враждебного отношения к данному народу. «Одной из примет языка вражды служат уничижительные наименования представителей другого этноса, распространенный в жаргонах, арго, просторечии, разговорной речи. ... Уничижительные номинации лиц другой национальности отражают нетерпимость говорящих, тяготеющую над ними власть предрассудков, суеверий, этнокультурных стереотипов.» (Грищенко, Николина 2006: 175).

Скорее таким примером уничижительной номинации можно рассматривать встречающуюся в речи литовцев Латвии (как, в частности, и литовцев, проживающих в Литве) форму для названия русских - производную с суффиксом -к- форму ruskis (ruskiai). Данная форма по своей структуре близка к русскому этнониму, но в литовском языке имеет место в разговорной речи и считается неприемлемой для нормированного ли- 
товского языка. Поэтому есть повод такое слово рассматривать в качестве конкурента [для] нейтрального этнонима, имеющего целью придать тексту определенную экспрессивность. «Возникновение экспрессивности у этнонимов невозможно без субъективно-эмоционального отношения к этим этносам, а субъективно-эмоциональное отношение зависит от социально-политической истории» (Грищенко, Николина 2006: 177). Как утверждают ученые, «в основу экспрессивного этнонима могут быть положены различные мотивировочные признаки, связанные с языковыми стереотипами, доминирующими в тот или иной исторический период. Особенности номинации представителей народов обусловлены общекультурной оппозицией «свой - чужой» и обычно отражают конфликты, существующие между этническими группами.» (Грищенко, Николина 2006: 184).

Более отдаленные, т. е., не основанных на употреблении разных по структуре слов того же корня конкуренты этнонимов выявляют записи, в которых встречается слово vietiniai («местные») в повествовании о проживающих на той же территории людей.

Vi e t in i a i jau čia nieko blogo pret mus neturi ka pasakyti. [Местные здесь ничего плохого о нас не имеют, что сказать] В.

Правда, данное слово нельзя безоговорочно воспринимать в качестве конкурента конкретного этнонима, так как в основном на определенной территории проживают представители разных национальностей. Оно может быть выбрано информантами сознательно - чтобы не объяснять, о людях какой национальности идет речь, или неосознанно, не задумываясь, что такое слово неинформативно.

\section{Заключительные замечания}

В ходе исследования топонимов установлено, что спектр топонимов не очень широк, доминируют названия обеих государств (Latvija «Латвия» и Lietuva «Литва»), а из конкретных населенных пунктов - места проживания и территориально близкие к ним. Достаточно редко упоминаются конкретные названия мест ссылки или заключения, а также другие места, так или иначе связанные с личным опытом информантов.

Функционирование этнонимов выявляет интересные тенденции проявления оппозиции «свой - чужой». Информанты преимущественно в положительном контексте рассказывают о своей национальности, т. е., литовцах (lietuviai). Все-таки очевидно, что лишь более широкий контекст дает представление об отношении говорящего к названному этнонимом народу. Часто упоминаются коренные жители Латвии, соседи по месту жительства латыши (latviai). Выборка материала дает возможность выяснить, как путем сравнения описываются литовцы и латыши. Кроме того, в речи литовцев встречаются названия тех народов, представители 
которых проживают вместе с литовцами, а также те, с которыми имеются устойчивые традиции общения. В данном случае речь идет о двух этнонимах - rusai («русские») и žydai («евреи»).

В качестве конкурентов, количество которых немногочисленное, функционируют в основном универсальные лексемы, подходящие для обозначения любого народа или места жительства (местоимение jie «они», существительное vietiniai «местные», антонимические обстоятельства места с̌ia «здесь» и ten «там»).

\section{БИБЛИОГРАФИЯ}

Ольга АХМАНОВА, 2004: Словарь лингвистических терминов. Москва: Едиториал УРСС.

А. И. ГРИЩЕНКО, Н. А. НИКОЛИНА, 2006: Экспрессивные этнонимы как приметы языка вражды. Язык вражды и язык согласия в соииокультурном контексте современности: коллективная монография. Отв. ред. И. Т. Вепрева, Н. А. Купина, О. А. Михайлова. Труды Уральского МИОНа. Вып. 20. Екатеринбург: Изд-во Урал. ун-та. 175-187.

Регина КВАШИТЕ, 2003а: Литовцы в Латвии: социолингвистический и лингвистический аспекты. Proceedings of the Third International Congress of Dialectologists and Geolinguists. Lublin, 24-29 July, 2000. Edited by Stefan Warchoł. Vol. 1. Lublin: Marie Curie-Skłodowska University Press. 395-405.

- -, 2003b: Названия реалий общественной жизни в речи литовцев Латвии. Języki mniejszości i języki regionalne. [Serija: Język na pograniczah. 24.] Red. E. Wrocławska, J. Zieniukowa. Warszawa: Slawistyczny Ośrodek Wydawiczny. 429-439.

СТАТИСТИКА - Centrālā statistikas pārvalde <http://data.csb.gov.lv/Dialog/Saveshow.asp> [2009 11 29]

ОНОМАСТИКА - <family-history.ru/material/onomastics/spravka/> [2009 11 29]

Laima ANGLICKIENĖ, 2006: Kitataučiu ịvaizdis lietuviu folklore. Vilnius: Versus aureus.

Alvydas BUTKUS, 1995: Latviai. Kaunas: Aesti.

Kazimieras GARŠVA, 2005: Lietuviu kalbos paribio šnektos (fonologija). Vilnius: Lietuvių kalbos instituto leidykla.

Elena GRINAVECKIENĖ, 1980: Daugpilio apylinkių lietuvių šnektos fonetika. Lietuviu kalbotyros klausimai XX. Vilnius. 223-238.

Regina KVAŠYTĖ, 1997: Latvijos lietuvių šnekamosios kalbos ypatumai. Acta Baltica'94. Kaunas: Aesti. 33-37. 
--, 2001: Apie kai kurias latvybes Latvijos lietuvių kalboje. Paribio tarmiu ir kalbu problemos. Tarptautinès mokslinès konferencijos, skirtos Europos kalbų metams, pranešimai. Šiauliai. 84-96.

- -, 2002: Latvijas lietuviešu leksikas īpatnības. Valoda-2002: Valoda dažādu kultūru kontekstā. Humanitārās fakultātes XII zinātniskie lasījumi. 1. daḷa. Valodas lingvistiskie aspekti. Atb. red. S. Murāne. Daugavpils: Saule. 47-53.

- -, 2006: Die Lexik der Litauer Lettlands: Erscheinungen von Sprachkontakten. Proceedings of the $4^{\text {th }}$ International Congress of Dialectologists and Geolinguists. Rīga: LU LVI. 313-318.

- -, 2007: Zemgales lietuvieši un to valodas specifika. Raksti III. Starptautiskās zinātniskās konferences Lielupes upes baseins: kultūrvēsturiskā nozìme un geogrāfiskais faktors, kopīgais un atšķirīgais referāti. Jelgava: G̣. Eliasa Jelgavas vēstures un mākslas muzejs. 41-45.

- -, 2009: Besonderheiten der Umgangssprache der Litauer Lettlands: Gebrauch der Präpositionen. Dialectologia and Geolinguistica. Volume 17, Issue 1. 38-51.

Jānis ROZENBERGS, 2005: Aizdaugavas leiši latviešu tautasdziesmās un viṇu etniskā piederība. Tautas un zemes latviešu tautasdziesmās. Rīga: Zinātne. 9-21.

Aleksandras VANAGAS, 1996: Lietuvos miestu vardai. Vilnius: Mokslo ir enciklopedijų leidykla.

Kazimieras ŽUPERKA, 1995: Kalbos priemoniu konkurencija kaip lietuviu kalbos stilistikos objektas: habilitacinis darbas. Šiauliai.

\section{TOPONIMI IN ETNONIMI V LEKSIKI LITOVCEV V LATVIJI}

Članek predstavlja rezultate raziskave leksike Litovcev v Latviji, zlasti toponimov in etnonimov. Cilj raziskave je bil pokazati, v kolikšni meri se pojavljajo geografska imena in imena narodnosti, ter ugotoviti, katere besede jih $\mathrm{v}$ govoru lahko nadomeščajo. Gradivo je bilo zbrano na obmejnem področju z Litvo (v okrajih Saldus in Dobele), pridobljeno pa tudi od Litovcev, živečih v Rigi.

Izsledki raziskave kažejo, da spekter toponimov ni širok, saj med posameznimi naselji in njim bližnjimi področji prevladujejo imena obeh držav (Latvija in Litva). Redko so bila omenjena imena krajev izgnanstva ali krajev prestajanja zaporne kazni, prav tako imena krajev, povezanih z informatorjevimi osebnimi izkušnjami.

Etnonimi razkrivajo zanimive težnje, ki izkazujejo nasprotje domače - tuje. Večina informatorjev goji pozitiven odnos do svoje, tj. litovske narodnosti, vendar je očitno, da stališče govorca do naroda, imenovanega $z$ etnonimom, predstavlja širši kontekst. Pogosto so omenjeni Latvijci in njihovi sosedje.

Zbrano gradivo omogoča primerjavo karakterizacije Litovcev in Latvijcev. V govoru Litovcev najdemo imena tistih narodnosti, katerih predstavniki živijo z njimi in ohranjajo nespremenljivo tradicijo komunikacije, na kar kažeta dva etnonima, Rusi in Judje. Med konkurenčnimi leksemi, ki ustrezajo poimenovanju katerega koli naroda ali naseljenega področja, velja omeniti zaimek oni, samostalnik domačini in protipomenska krajevna prislova $t u$ ter tam. 